\title{
Jerarquía de valores en la mujer trabajadora
}

\section{INTRODUCCION}

El presente trabajo es parte de una invastigación mî์ extensa, en que se analizabar las actitudes sociales, familiares, politicas y personales de una amplia muestra de mujeres trabajadorm ("). A partir de unta pregunta del cuestionario - pregunta que trataba de locallzar los valores fundamentales de las encuestadas- "se imtenta ahora profundizar en la estructura de osos valores y su significado para un colectivo tan particular como os la mujer trabajadora.

Sólo se pretende, por tanto, analizar comparativamente y con mayor detenimiento el seruido, ordenamiento $y$ ponderación que la mujer crabajadora conced a deter" minados valores de manejo ordinaro en muestra sociedad.

\section{Altonso Lopez Caballero Profesor de Sociologia de ETEA}

\section{EL TEMA DE LOS VALORES}

Hay que comenzar por admitir que el valor, como ámbito especifico de refiexión, es una preocupación reciente. Es cierto, sin embargo, que la idea platónica de la justicia o el amor cristiano son en el fondo auténticos valores.

De hecho, si se analiza el núcleo ideológico de todos los grandes pensadores religiosos -Confucio, Buda, Lao Tsé, Jesús de Nazaret, los profetas de israel-, se descubre que todos confluyen en unas cuantas ideas clave. Se trata de auténticos valores, muy simples pero profundamente humanos: todos ellos ponen como esencial la búsqueda de la verdad, el amor fraterno, la sencillez, el altruismo y la reducción del sufrimiento humano.

* Dicha investigación dirigida por el autor del articulo fue realizada por la Srta M." Carmen López Martín, Srta. Amparo Simón Valero y José Carlos Moreno Ramirez. 


\section{Arfonso López Cahallero}

Pero el valor, como objeto específico de análisis, no aparece hasta el siglo XIX. Se trata de una adquisición tardía del filosofar humano.

Se podrían marcar tres direcciones globales en la interpretación del valor, desce su nacimiento. Una primera interpretación de tipo subjetivista, una segunda que intenta objetivar los valores y la tercera que planiea el problema pragmático del valor como transfondo de toda ciencia.

1. En la primera corriente se puede encontrar Lotze - "los valores no son sino que valen"- Brentano y sus discípulos Meinong y Ehrenfess, y Nietzsche. Para éste, es necesaria "una trasmutación general de los valores" de modo que la cultura cristiana deje paso a otra nueva (1).

El positivismo lógico imprime también una dirección subjetivista a los valores. Wittgenstein, por ejemplo, afirma que "no nos referimos a objetos sino a simples estados de ánimo".

$Y$ para Bertrand Russell, los valores están enteramente fuera del conocimiento (2): "no se trata de verdades sino de lógica, a la negación del pecado. Para él, carece totalmente de sentido la norma ética o el principio moral. Un encuadre similar ofrece el existencialismo, con Sartre a la cabeza. No existe moralidad sino angustia ética.

2. La segunda dirección está centrada en Max Scheller (3) y pretende establecer con nítidez la doctrina objetiva de los valores.

"Hay auténticas y verdaderas cualidades de valor que representan un dominio propio de objetos y que pueden ser, como cualidades de valor más altas y más bajas. Puede haber también entre ellas un orden y una jerarquía, independientes de un mundo de bienes en que se manifiestan y también independientes de las modificaciones que ese mundo de bienes sufra a través de la historia. Respecto a la experiencia de ese mundo de los bienes, los valores son a priori".

Se trata, por tanto, de cualidades irreales pero objetivas, independientes de los objetos que las poseen y con existencia propia al margen de dichos objetos. Según Scheller, se presentan en una jerarquía ordenada. En la tabla elaborada por él aparecen en la cúspide los valores religiosos y en la base los valores útlles.

3. La tercera corriente se planteó en 1911, cuando Durkheim distinguió claramente entre juicios de valor y juicios de realidad. ¿Pueden separarse

(1). Frondizi: ¿Qué son los valores?, Ed. Fondo de Cultura Económica, México 1958,36 1965

(2). Bertrand Russell: Religión y Ciencia, Ed. Fondo de Cultura Económica, México

(3). Max Scheller: Etica, tomo I, Revista de Occidente, Madrid 1941. 


\section{Jorarquía de valores en la mujer trabajadora}

claramente ambos? ¿Puede el científico o el pensador desembarazarse totalmente de su mundo de valores para abordar objetivamente la realidad? ¿Debe hacerio?

Desde 1914, agudizada sin duda por el peso de los dos grandes bloques, perdura hasta nuestros días una polémica sobre la neutralidad o el compromiso axiológico de la ciencia social. En ella han participado nombres tan conocidos como Max Weber, Rickert, Leo Strauss, Raymond Aron, Dahrendorf, Mannheim...

\section{POSIBLES ENFOOUES DEL VALOR}

Puede que, desde el punto de vista pragmático de un utilitarismo rastrero, el valor aparezca como un ente abstracto, filosófico o pertenenciente al nebuloso terreno de la ética. Sin embargo, dado su carácter inseparable del hombre en cuanto ser social y pensante, el valor encierrra otros muchos enfoques distintos del meramente filosófico. Estos son algunos.

\section{Como fuente motivacional}

Entre las teorias de la motivación, las hay bien diversas (4). Está, por ejemplo, a) la teoria mecanicista del estímulo-respuesta, b) la hipótesis fisiológica (la conducta está determinanda por alteraciones químicas que tienen lugar en el organismo), c) la teoría del instinto (determinadas tendencias innatas y universales guian el comportamiento), d) la hipótesis hedonística (toda explicación de la conducta hay que buscarla en la tendencia del organismo hacia el placer).

Finalmente, e) la teoría voluntarista, en la que el "querer" se considera una base importante de la conducta humana. Según esta teoría, la conducta refleja la voluntaria expresión de un valor consciente que se persigue. Evidentemente, esta teoría presupone la responsabilidad individual en la toma de decisión.

\section{Como necesidades personales a satisfacer}

Detrás de las famosas necesidades del hombre, estructuradas magistralmente por Abraham Maslow, laten determinados valores evidentes. Detrás de la necesidad de seguridad está la paz y el orden. Detrás de la necesidad de pertenencia está el afecto, la aceptación, la donación. Detrás de la necesidad de estimación está el prestigio, el éxito, el auto-

(4). Crow and Crow: General Psychology, Littlefield, New Jersey, 1972, 135. 


\section{AlTonso López Caballero}

rrespeto. Detrás de la necesidad de autorrealización está la estabilidad, el crecimiento personal.

En su libro "El hombre autorrealizado" (5), Maslow plantea que no debemos decir "debería escoger esto o aquello", sino más bien "las personas saludables, cuando se les permite escoger libremente, eligen esto o aquello", que es lo mismo que preguntar: "¿cuáles son en realidad los valores de los mejores seres humanos?".

De un modo patente, vincula la autorrealización -máxima necesidad del hombre según él- con la adhesión a determinados valores. Y estos valores clave hay que deducirlos por la experiencia de las personas autorrealizadas. Cita la frase de Aristóteles: "son las cosas que resultan agradables y valiosas para un hombre bueno, las que realmente son agradables y valiosas".

\section{Como distintivo diferencial de una cultura}

Como contraposición a la teoría de las necesidades, hay autores (6) que creen que es el valor, no una serie de necesidades, lo que subyace a toda conducta humana. La premisa de que el hombre actúa para satisfacer necesidades presupone - según ellos - una concepción negativa del bien, como corrección de un estado indeseable.

De ese modo, la cultura no sería la respuesta a necesidades concretas de una sociedad sino el sistema que sostiene y expresa los valores básicos de dicha sociedad. Los valores serían entonces los criterios que dan sentido y significado a la cultura y a la sociedad total.

Desde este punto de vista, los valores encerrarían en sí una potente fuerza motivante, generadora de cambios y reestructuraciones en el tejido social. Porque, analizándolo detenidamente, el valor posee las siguientes características: 1) es algo que se comparte, 2) se considera importante para la sociedad, 3) implica emociones individuales y colectivas. Las tres características son poderosas palancas motivacionales.

\section{Como flash de la propia posición vital}

El valor puede ser, sin duda, expresión plástica de la propia cosmovisión, posición vital o "weltanschauung". Constituye así como una instantánea de nuestra postura preferida ante la vida. Cualquier valor imaginable puede servirnos para definir a otra persona de una sola pincelada. Así podemos decir de alguien que "rebosa paz", que "irradia estabilidad" o que "contagia dulzura".

(5). Abraham Maslow: Ei hombre autorrealizado, Ed. Kairos, Barcelona 1973, 214.

(6) Kluckhohn, Murray \& Schneider: "Personality in nature, society and culture", Alfred Knopt, New York 1956, 335 ss. 
Jerarquía de valores an la mujer trabajadora

En definitiva, los valores no sólo expresan sino que dan sentido a la propia vida. Viktor Frankl (7) lo expresa así:

"Al tratar del problema del sentido de la vida distinguimos en términos muy generales tres posibles categorías de valores. Valores de creación, valores de vivencia y valores de actitud. La primera categoría se realiza por medio de actos, la segunda mediante la acogida pasiva del universo (la naturaleza, el arte). Por su parie, los valores que llamamos de actitud se realizan siempre que admitimos como tal algo que consideramos irremisible, fatal como el destino. Con arreglo al modo como cada uno lo acepta se abre ante nosotros una muchedeumbre inmensa de posibilidades de valor. Lo cual quiere decir que la vida del hombre no se colma sólamente creando y gozando, sino también sufriendo".

\section{Como estructura de la propia personalidad}

Abram Kardiner (8) habla de una "personalidad básica", configurada en las primeras experiencias infantiles y mediatizada por los valores transmitidos inconscientemente por la familia y el entorno social.

Por su parte, Allport y Vernon crearon (1951) un instrumento para diseñar el perfil de personalidad de un sujeto (9), basándose en los seis valores sugeridos ya por Spranger (1928):

- Valores teoréticos. Descubrimiento de la verdad a través de acerca. mientos empíricos, críticos y racionales.

- Valores prácticos. Importancia a lo útil, pragmático y económico.

- Valores estéticos. Gozo de la armonía, belleza, simetría y contemplación.

- Valores sociales. Actitudes humanitarias, dominadas por el altruismo y la filantropia.

- Valores de poder. Interés en el prestigio, influencia y renombre.

- Valores religiosos. Centramiento en las experiencias místicas, de unión con el cosmos o de trascendencia al más allá.

\section{Como edificación de una suficiente felicidad}

Si el hombre persigue los valores, podemos aventurar sin riesgo a equivocarnos que los persigue para ser feliz. El quid de la cuestión radica

(7). Viktor E. Frankl: Psicoanálisis y Existencialsmo, Ed. Fondo de Cultura Económica, México 1967, 131

(8). Abram Kardiner: The Psychological Frontiers of Society, Columbia University Press, New York 1945.

(9). Theodore Newcomb: Social Psychology, Holt, Rinehat \& Winston, New York 1965,139 
en acertar en la elección de unos valores y en el rechazo de otros. Dada la panorámica que se divisa a nuestro alrededor, parece que dicha elección no es tan fácil.

Nadie como Erich Fromm ha profundizado en el tema (10). En numerosos libros, diseña lúcidamente la estrategia necesaria para llevar a cabo esa pautatina elección de valores. Enunciemos algunos de los que Fromm considera fundamentales:

- Relación versus narcisismo,

- Creatividad versus destructividad,

- Amor fraterno versus simbiosis incestuosa,

- Individualidad versus gregarismo,

- Razón versus irracionalidad,

- Amor a la vida versus amor a la muerte.

\section{Como concrección de actitudes}

Aunque las actitudes particulares pueden hundir sus raíces en multitud de específicos motivos, se pueden agrupar en cuatro grandes bloques las funciones según las cuales se estructuran las actitudes personales.

A. Función de ajuste o equilibrio. Muchas actitudes se crean sencillamente para conseguir metas deseables y para evitar consecuencias indeseables. Se trata de maximizar las recompensas y minimizar las sanciones.

B. Función defensiva del yo. Hay también actitudes que nacen de determinados mecanismos, por medio de los cuales el individuo se defiende de sus impulsos inaceptables, de su angustia, su descontrol o su libido.

C. Función clarificadora. Algunas actitudes tienen relación con la necesidad de proporcionar sentido al propio mundo y de contar con standards de referencia, para evitar lo que de otro modo sería un universo caótico.

D. Función expresiva de valores. Mientras unas actitudes tienen como finalidad ocultar asimismo a los demás el lado oscuro del propio yo, otras actitudes pretenden ser la expresión positiva de los valores nucleares y de la clase de persona que uno quiere ser.

La relación existente entre impulso, motivo, actitud y valor podría razonablemente estructurarse asi: $1^{\circ}$ ) Impulso (estado del organismo que inicia una tendencia hacia la actividad), $2^{\circ}$ ) motivo (tendencia aprendida y

(10) Erich Fromm: Psicoanálisis de la sociedad contemporánea. Ed. Fondo de Cultura Económica. México 1971, 32 . 


\section{Jerarquía de valores en la mujer trabajadora}

orientada hacia una meta, activada por el impulso), $3^{\circ}$ ) actitud (estado generalizado por la repetición de determinanda conducta motivada), 49) valor (meta inclusiva alrededor de la cual se agrupan y organizan determinadas pautas de actitudes).

\section{CARACTERISTICAS DE LA MUESTRA ANALIZADA}

La pregunta que proporciona los datos que se estudiarán a continuación forma parte de un cuestionario mucho más amplio, sobre actitudes personales y sociales, realizado en año 1989 en la provincia de Córdoba.

Esta era la pregunta concretamente:

"Ordena los siguientes valores, según la importancia que tengan para $\mathrm{ti}$, sabiendo que el número 10 es el más importante y el número 1 el menos importanie:

- Matrimonio

- Amistad

- Dinero

- Trabajo

- Religión

- Amor

- Cultura

- Sexo

- Maternidad

- Libertad

La muestra estaba formada por 207 mujeres trabajadoras, tanto por cuenta propia como asalariadas, con edades comprendidas entre los $16 \mathrm{y}$ los 65 años. El ámbito de la muestra fue Córdoba capital - 106 trabajadoras-y provincia - 101 trabajadoras. En concreto, las trabajadoras de la provincia pertenecian a 16 poblaciones diferentes.

Para la selección de la muestra se utilizó la técnica de muestreo aleatorio simple y proporcional, intentando adecuar las cantidades a las proprocionadas por la Encuesta de Población Activa del INE. Se administró el cuestionario por entrevista.

El estado civil de las encuestadas se repartía según el cuadro siguiente:

Solteras

Casadas

Viudas

\begin{tabular}{ccc} 
Capital & Provincia & Total \\
\hline 49 & 55 & 104 \\
56 & 45 & 101 \\
1 & 1 & 2
\end{tabular}




\section{Alfonso López Caballero}

La edad de las encuestadas viene expresada en el gráfico que sigue, desglosado según los bloques básicos de capital y provincia.

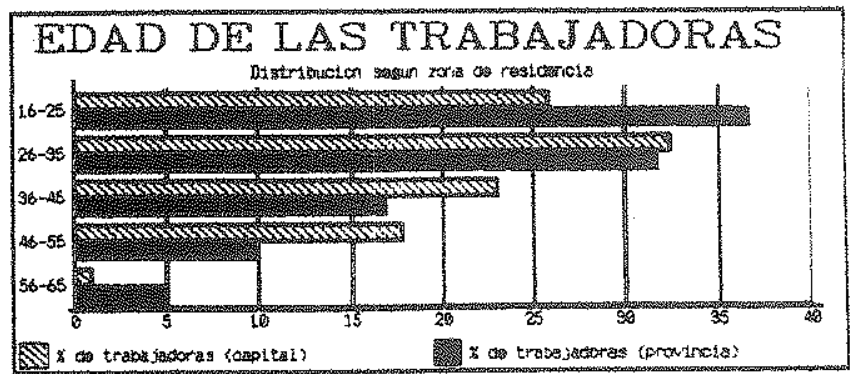

En cuanto al trabajo realizado, ésta es la relación concreta: dependien tas 34 , administrativas 32 , profesoras 30 , empleadas de hogar 24 , operarias de fábrica 20 , negocio propio 16 empleadas de banca 13 , ATS 10 , modistas 8 , técnicas de ordenador 4 , empleadas de laboratorio 4 , peluqueras 3 , camareras 2, farmacéuticas 2 , médicas 2, telefonista 1, pescam dera 1 , frutera 1.

El nivel de estudios se encuentra expresado en el siguiente gráfico:

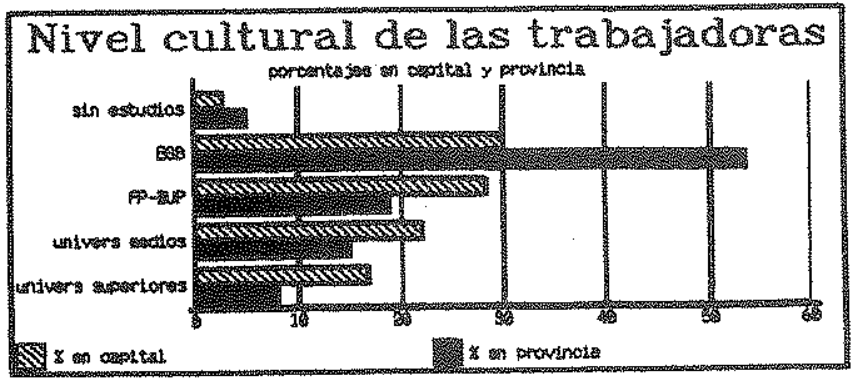

\section{RESULTADOS CUANTITATIVOS}

A continuación se exponen los datos obtenidos, agrupados en tablas. Más abajo se expresarán estos mismos datos en gráficos. 
Jerarquúa de valores an la mujer trabalidora

\section{CAPITAL.}

\begin{tabular}{lrrrrrrrrrr} 
Puntuación & 10 & 9 & 8 & 7 & 6 & 5 & 4 & 3 & 2 & 1 \\
\hline Matrimonio & 13 & 16 & 15 & 9 & 3 & 14 & 10 & 9 & 14 & 3 \\
Amistad & 10 & 13 & 21 & 21 & 18 & 11 & 7 & 2 & 0 & 3 \\
Libertad & 17 & 12 & 7 & 11 & 10 & 15 & 13 & 12 & 6 & 3 \\
Trabajo & 4 & 7 & 7 & 14 & 21 & 15 & 13 & 13 & 8 & 4 \\
Sexo & 1 & 0 & 4 & 6 & 3 & 3 & 14 & 13 & 15 & 47 \\
Amor & 34 & 22 & 20 & 11 & 8 & 8 & 2 & 0 & 1 & 0 \\
Religión & 6 & 9 & 8 & 10 & 10 & 9 & 8 & 12 & 13 & 21 \\
Cultura & 3 & 7 & 8 & 12 & 19 & 15 & 18 & 7 & 13 & 4 \\
Maternidad & 15 & 14 & 10 & 6 & 12 & 8 & 10 & 16 & 9 & 6 \\
Dinero & 0 & 5 & 4 & 8 & 6 & 12 & 11 & 19 & 27 & 14
\end{tabular}

PROVINCIA

\begin{tabular}{lrrrrrrrrrr} 
Puntuación & 10 & 9 & 8 & 7 & 6 & 5 & 4 & 3 & 2 & 1 \\
\hline Matrimonio & 6 & 10 & 9 & 7 & 12 & 8 & 13 & 20 & 9 & 7 \\
Amistad & 14 & 18 & 13 & 19 & 17 & 7 & 5 & 5 & 3 & 0 \\
Libertad & 11 & 14 & 17 & 14 & 16 & 9 & 11 & 5 & 4 & 0 \\
Trabajo & 4 & 14 & 19 & 14 & 13 & 14 & 10 & 10 & 2 & 1 \\
Sexo & 4 & 4 & 3 & 2 & 6 & 11 & 9 & 10 & 13 & 39 \\
Amor & 35 & 21 & 11 & 4 & 14 & 5 & 4 & 2 & 1 & 4 \\
Religion & 10 & 7 & 10 & 6 & 4 & 8 & 12 & 9 & 10 & 25 \\
Cultura & 6 & 5 & 11 & 13 & 16 & 13 & 16 & 13 & 5 & 3 \\
Maternidad & 8 & 6 & 4 & 14 & 9 & 12 & 15 & 12 & 15 & 6 \\
Dinero & 2 & 7 & 5 & 7 & 8 & 11 & 10 & 11 & 25 & 15
\end{tabular}

TOTAL CAPITAL Y PROVINCIA

\begin{tabular}{lrrrrrrrrrr} 
Puntuación & 10 & 9 & 8 & 7 & 6 & 5 & 4 & 3 & 2 & 1 \\
\hline Matrimonio & 19 & 26 & 24 & 16 & 15 & 22 & 23 & 29 & 23 & 10 \\
Amistad & 24 & 31 & 34 & 40 & 35 & 18 & 12 & 7 & 3 & 3 \\
Libertad & 28 & 26 & 24 & 25 & 26 & 24 & 24 & 17 & 10 & 3 \\
Trabajo & 8 & 21 & 26 & 28 & 34 & 29 & 23 & 23 & 10 & 5 \\
Sexo & 5 & 4 & 7 & 8 & 9 & 14 & 23 & 23 & 28 & 86 \\
Amor & 69 & 43 & 31 & 15 & 22 & 13 & 6 & 2 & 2 & 4 \\
Religión & 16 & 16 & 18 & 16 & 14 & 17 & 20 & 21 & 23 & 46 \\
Cultura & 9 & 12 & 19 & 25 & 35 & 28 & 34 & 20 & 18 & 7 \\
Maternidad & 23 & 20 & 14 & 20 & 21 & 20 & 25 & 28 & 24 & 12 \\
Dinero & 2 & 12 & 9 & 15 & 14 & 23 & 21 & 30 & 52 & 29 \\
& & & & & & & & & & \\
& & & & 191 & & & & & & \\
\hline
\end{tabular}


Alfonso López Caballero

RANKING DE MEDIAS

\begin{tabular}{|c|c|c|}
\hline Capital & Provincia & Total \\
\hline 1. Amor $(8,24)$ & Amor $(7,84)$ & Amor $(8,04)$ \\
\hline 2. ${ }^{0}$ Amistad $(6,91)$ & Amistad $(7,1)$ & Amistad (7) \\
\hline 3. ${ }^{\circ}$ Libertad $(6,12)$ & Libertad $(6,71)$ & Libertad $(6,41)$ \\
\hline 4. ${ }^{2}$ Matrimonio $(6,07)$ & Trabajo $(6,33)$ & Trabajo $(5,84)$ \\
\hline 5."Maternidad $(5,87)$ & Cultura $(5,55)$ & Matrimonio $(5,62)$ \\
\hline 6.9 Trabajo $(5,37$ & Matrimonio $(5,15)$ & Maternidad $(5,49)$ \\
\hline 7. Cultura $(5,22)$ & Maternidad $(5,05)$ & Cultura $(5,38)$ \\
\hline 8. Religión $(4,67)$ & Religión $(4,64)$ & Relligión $(4,66)$ \\
\hline 9. Dinero $(3,75)$ & Dinero $(4,09)$ & Dinero $(3,92)$ \\
\hline $10 .{ }^{-} \operatorname{Sexo}(2,73)$ & Sexo $(3,33)$ & Sexo $(3,02)$ \\
\hline
\end{tabular}

\section{GRAFICOS TOTALES Y PARCIALES}

A. Ranking de las valoraciones.
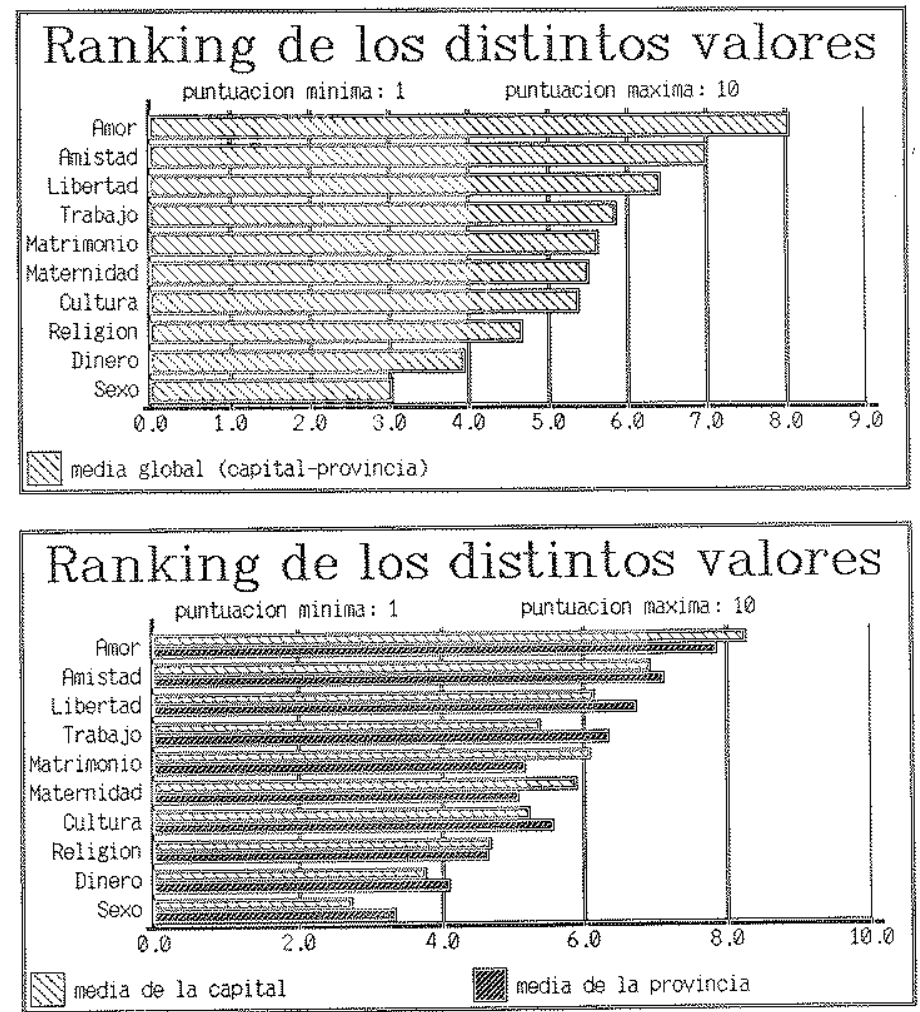
Jerarquía de valores en la mujer trabajadora

B. Puntuaciones otorgadas a cada uno de los valores.

Gráficos escorados:
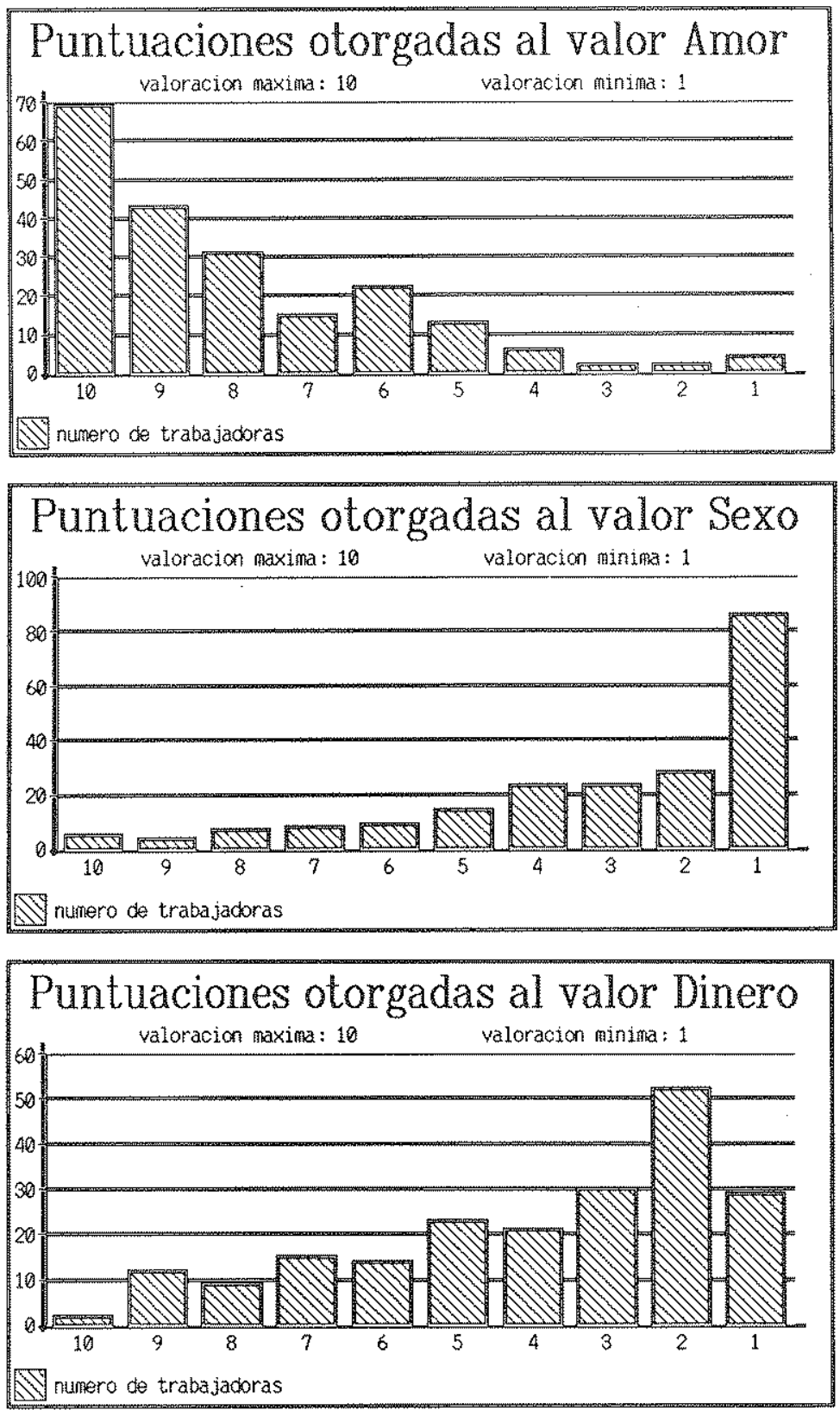
Graficos de doble colina
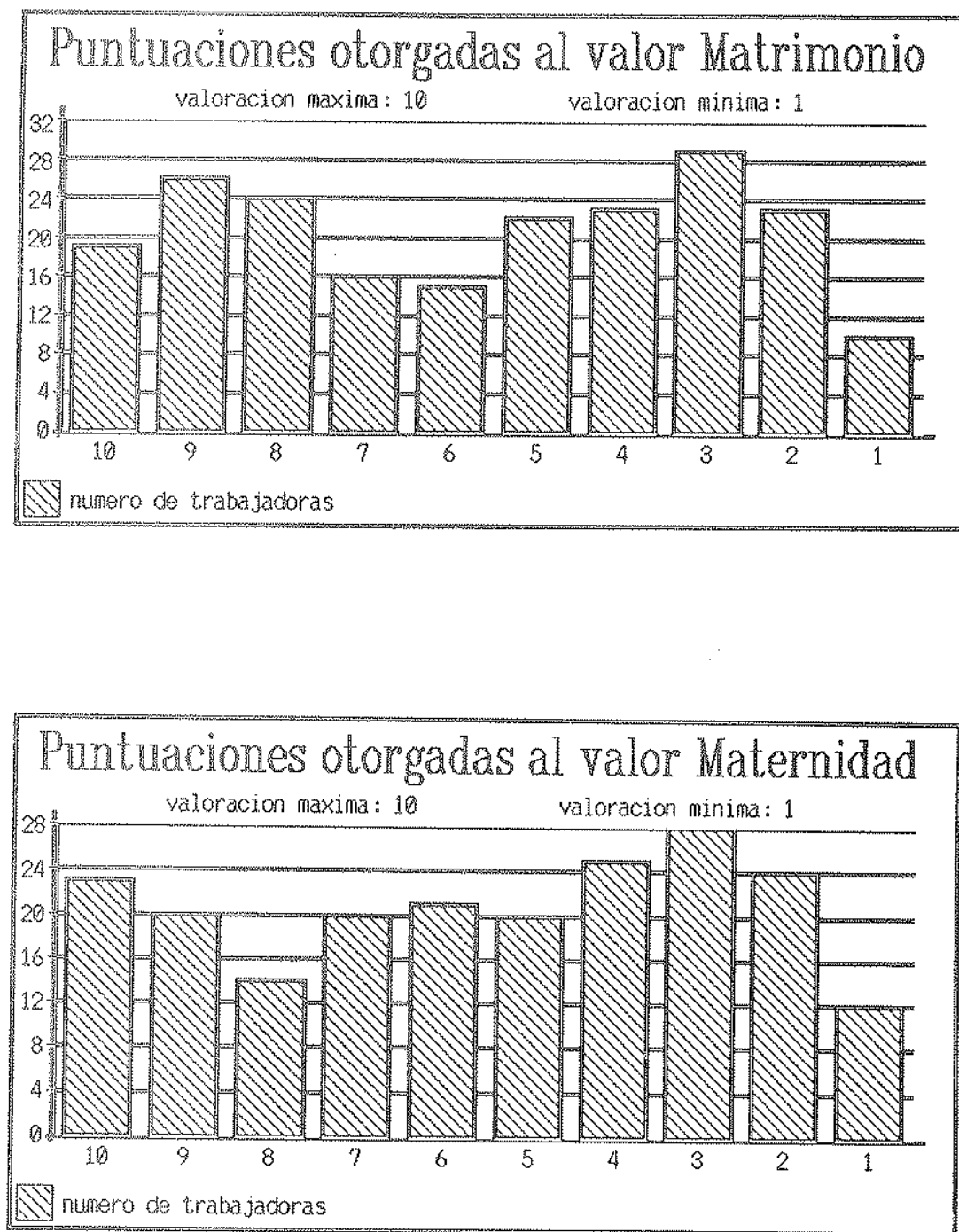


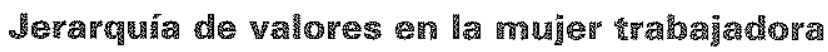

Gráficos en campana:
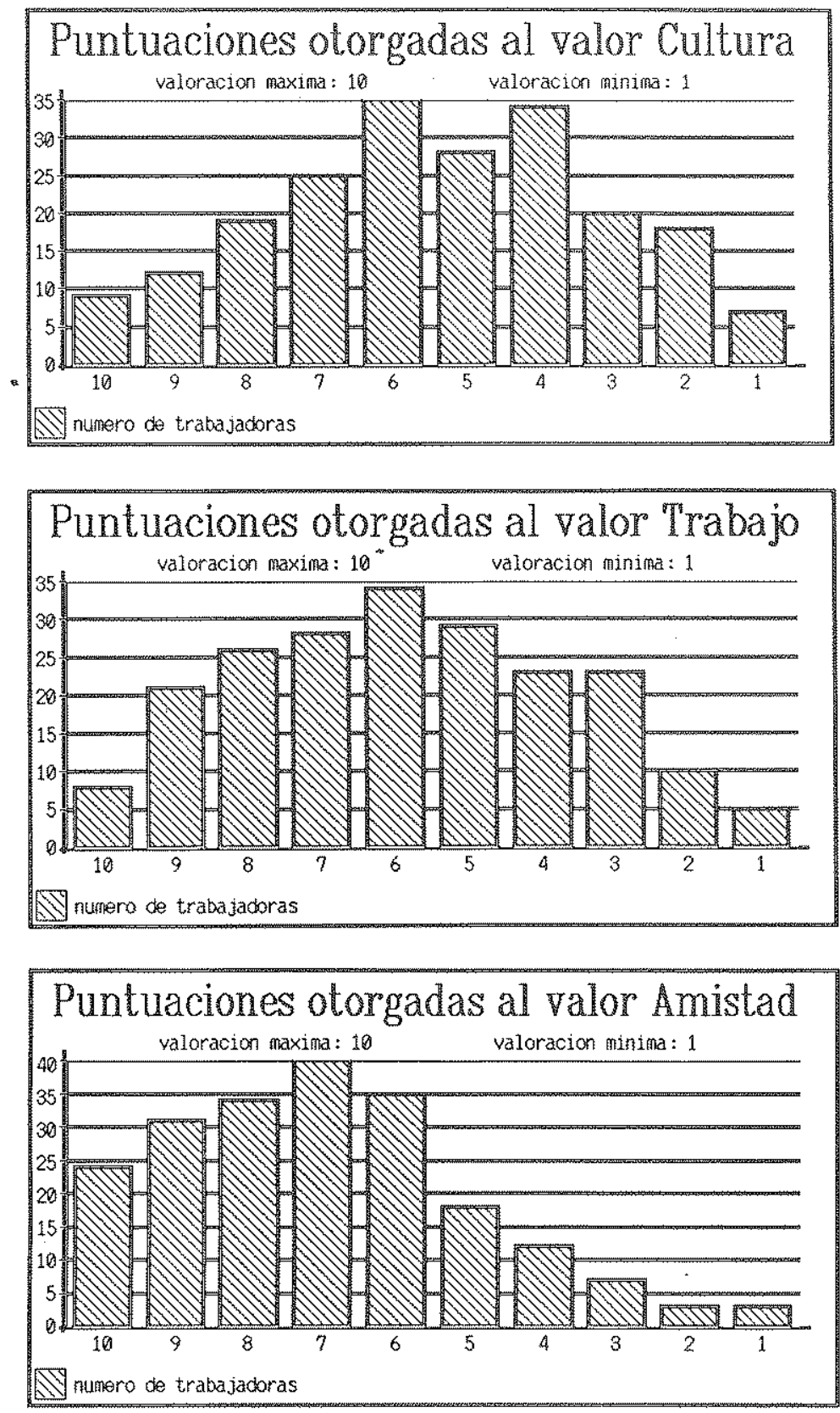
Gráficos en meseta:
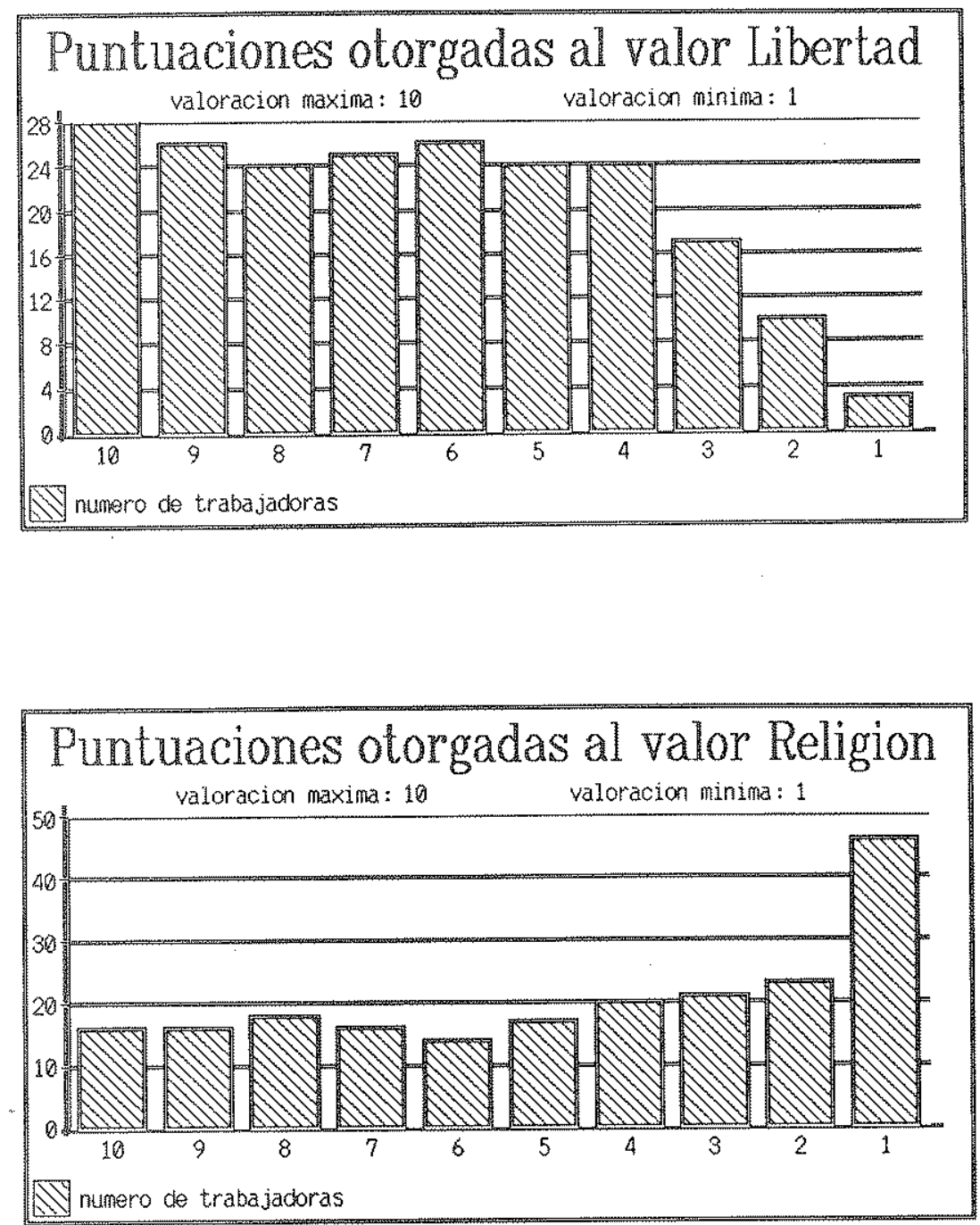
Jerarcufia de valores en la muger trabajadora

C. Comparaciones resaltables.
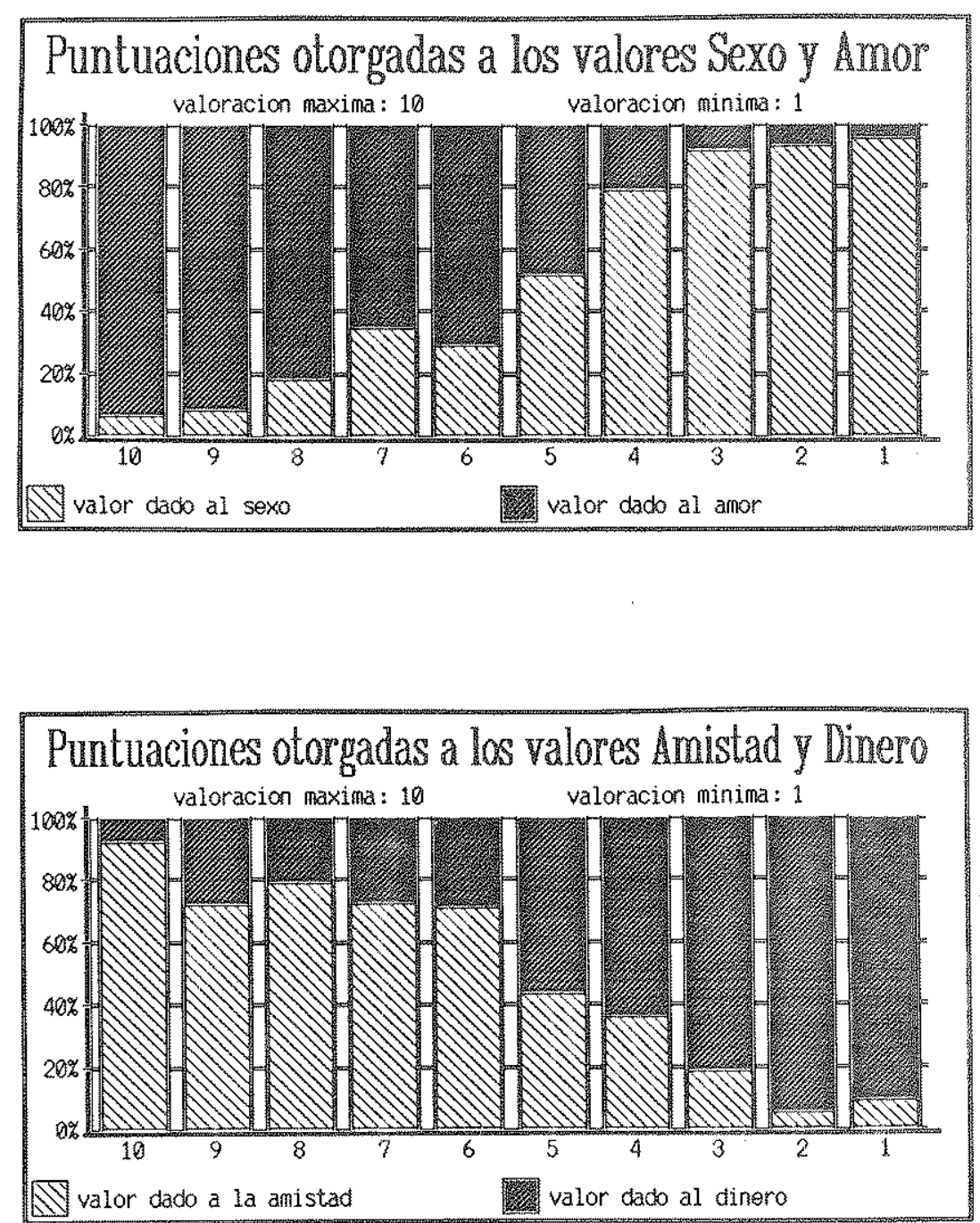

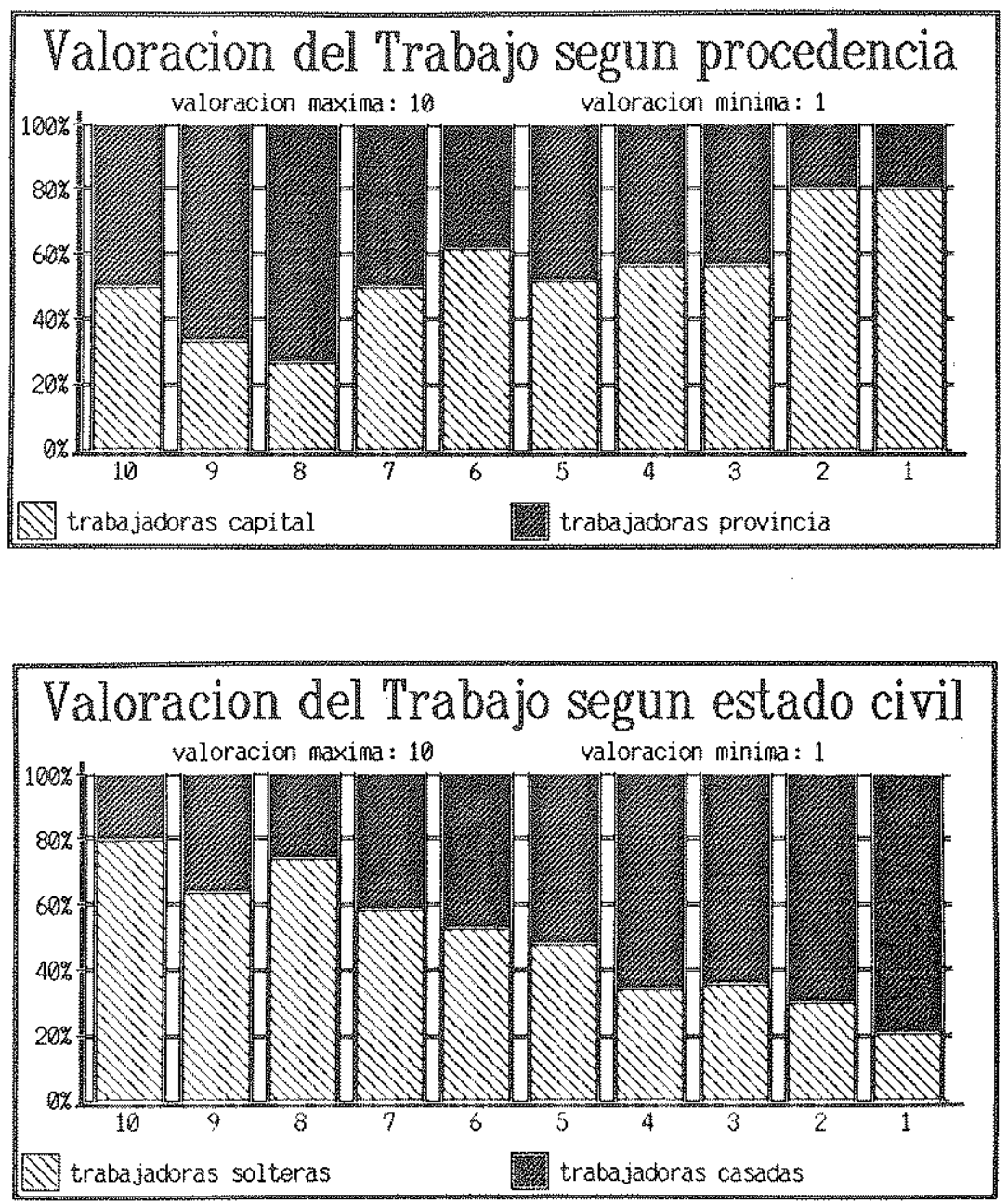


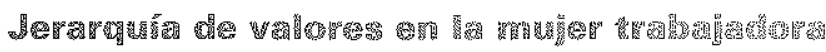

\section{CONCLUSIONES}

A la vista de los diferentes gráficos, se pueden establecer las siguientes conclusiones:

1. Los tres valores más estimados son el amor, la amistad y la libertad. Los tres podriamos agruparlos en la categoria de "valores de significado" (11), es decir, aquéllos en que la realidad se mestra con cualidades que son importantes para la temática de la existencia individual.

Los tres valores menos estimados son la religión, el dinero y el sexo. Es de notar que tanto en los tres primeros como en los mes uthmos axiste coincidencia a la capital y a la provincia. Es decir, las trabajadoras de la capital y de la provincia coinciden en sus tres elecciones primeras y sus tres elecciones últimas.

2. Se produce un claro distanciamiento hacia arriba en los tres primeros valores y un claro descenso en los tres últimos, mantenténdose los cuatro restantes intemedios en una puntuación muy similar (en tomo al 5,5 de media).

Asimismo, en los cuatro valores intermedios se dá una manifiesta disparidad, en cuanto a su puntuación, en la capial y en la provincia.

3. El matrimonio, uno de estos valores intermedios, resula mucho más estimado en la capial que en la provincia. Existe, entre las medias respectivas, diferencia estadisticamente significativa a un nivel de confianza del $1 \%(p<0,01)$.

4. Por el contrario, el trabajo es más valorado en la provincia. Entre ambas medias, de la capital y la provincia, existe diferencic estadisticamente significativa al nivel de confianza del $1 \%(p<0,01)$.

5. La maternidad obtiene mejor puntuación en la capital, siendo la diferencia de medias estadísticamente significativa a un nivel de confianza del $5 \%(p<0,05)$.

6 . Existen valores cuyos gráficos están claramente escorados a la izquierda o la derecha. Asi, por ejemplo, el amor, el dinero o el sexo. Elo indica una casi unanimidad valorativa, tendente a los extremos, en el conjunto de la población. Podemos, por tanto, predecir en gran medida su fuerza motivacional para la mayor parte del tejido social.

7. Existe otro equipo de valores cuyas puntuaciones más votadas son precisamente las intermedias. Producen gráticos en campana. Elemplos 188.

(11). Philipp Lersch; La estructura de la personalidad, Ed. Scientia, Barcelona 1964, 


\section{Atronso López Caballero}

son el trabajo, la cultura, la amistad. Supone este resultado que tales valores son considerados por el bloque mayoritario de trabajadoras como válidos pero secundarios, como valores de segunda categoría pero nada desdeñables.

8. La libertad y la religión son dos valores que obtienen un reparto casi igualitario en todas las puntuaciones, teniendo en cuenta que la mesefa de la libertad es apuntada a la izquierda (puntuación alta) y que la meseta de la religión es apuntada a la derecha (puntuación baja). Se da en la muestra casi al mismo número de trabajadoras que votan cada una de las puntuaciones. La conclusión, por tanto, es que se reparten de modo igualitario las trabajadoras que estiman mucho tales valores, las que los estiman moderadamente y las que no los estiman en absoluto.

9. El matrimonio y la maternidad tienden a conseguir puntuaciones mayoritariamente altas o bajas, pero sin llegar a los extremos. Es lo expresado en el gráfico de doble colina. Ambos valores obtienen mucha mejor puntuación en la capital que en la provincia. Por contra, la libertad y el trabajo son más valorados en la provincia.

10. Según el estado civil, se descubre una distinta valoración del trabajo: obtiene mucho mejores puntuaciones entre las solteras que entre las casadas. 